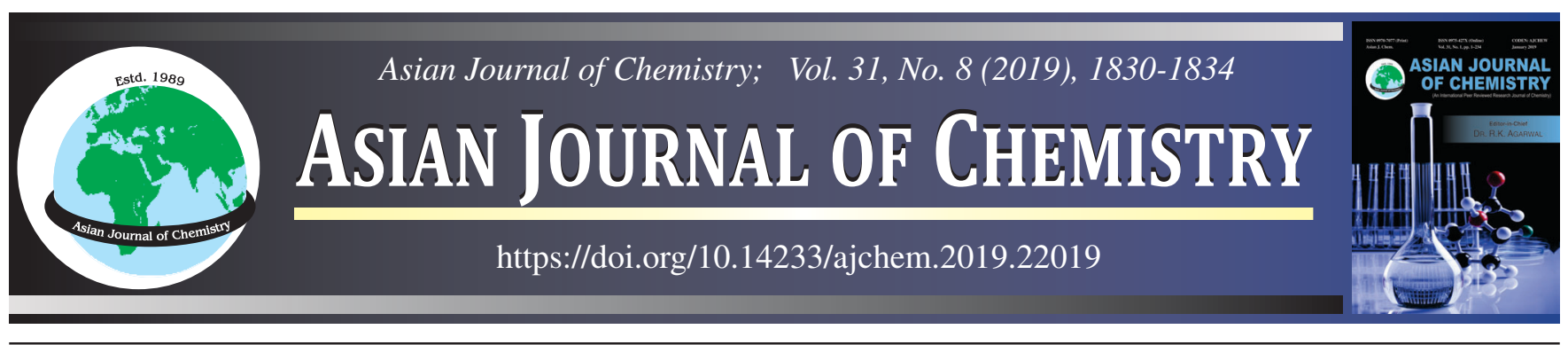

\title{
Phytochemical Contents and Antioxidant Capacity of the Leaves of Aloe greatheadii var. davyana from Four South African Provinces
}

\author{
Sechene S. Gololo*, Denga Nthai and Motetelo A. Mogale
}

Department of Biochemistry, Sefako Makgatho Health Sciences University, P.O. Box 235, Medunsa 0204, Ga-Rankuwa, Pretoria, South Africa

*Corresponding author: Tel: +27 12 5214372; E-mail: Stanley.gololo@smu.ac.za

Received: 21 February 2019;

Accepted: 22 April 2019;

Published online: 28 June 2019;

AJC-19461

The current study was aimed at the determination of the phytochemical contents and antioxidant capacity of the leaves of $A$. greatheadii from four provinces of South Africa. The leaves samples of A. greatheadii were collected at four different locations in South Africa; namely, Limpopo province (Polokwane), Gauteng province (Ga-Rankuwa), Mpumalanga province (Siyabuswa) and North-West province (Brits) during the summer season of the year. The ground samples were then extracted in a serial sequential procedure with different organic solvents using cold maceration extraction method. The extracts were then subjected to quantitative phytochemical analysis for the determination of total phenolic, total tannin, total flavonoid and total saponin content. In addition, the antioxidant capacity of the methanol extracts were evaluated through the DPPH assay. Quantitative phytochemical analysis showed variation in the total phenolic, total tannin, total flavonoid and total saponin contents of the samples from different locations, with specific phytochemicals found in higher amounts at different locations. However, upon calculation of the total phytochemical content the high amount was recorded with the Limpopo province sample. Variation in the antioxidant capacity $\left(\mathrm{EC}_{50}\right.$ based) of the samples from different locations was demonstrated, with the Limpopo and Mpumalanga provinces' samples showing high capacity. The results demonstrated that the variation in geographical locations has an effect on the phytochemical contents and antioxidant capacity of the leaves of A. greatheadii. Furthermore, the Limpopo province area with a high altitude appeared to be providing suitable growing conditions for high accumulation of phytochemicals and higher antioxidant capacity.

Keywords: Aloe greatheadii, Phytochemical content, Antioxidant capacity, Geographical location, Altitude.

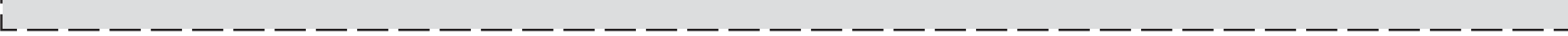

\section{INTRODUCTION}

The usage of plants for human and animal healthcare purposes dates back many decades ago. Medicinal plants possess many compounds within their different parts known as phytochemicals that possess biological activities that exert physiological responses in living systems which, are health beneficial to organisms [1]. As such, it is the nature of phytochemicals present in different plant parts that contributes to their medicinal importance. The biosynthesis and accumulation of phytochemicals, which informs the phytochemical composition, in plants is reported to be influenced by environmental factors such as geographical locations, seasonal variations and cultivation aspects under which the plants are growing $[2,3]$.

Aloe plants are the most common or popular medicinal plants used for traditional medicine purposes. Their extracts are used traditionally for treatment of arthritis, skin cancer, burns, eczema, psoriasis, digestive problems, high blood pressure and diabetes [4]. Aloes in general are known for their antioxidant properties attributed to the presence in this plants of organic acids, polyphenols/phenolic acids, alcohols, aldehydes, ketones, pyrimidines, indole alkaloids, phytosterols and dicarboxylic acids [5]. Since aloes are generally popular amongst South African traditional health practitioners and general usage by communities, the choice of the species for collection is often informed by easy access and availability.

Amongst the aloes, Aloe greatheadii var. davyana is the most widely distributed in all the northern provinces of South Africa that include Limpopo, Gauteng, Mpumalanga and NorthWest provinces, although its therapeutic properties are not well documented [6]. This wide distribution in different geographical locations exposes the plant species to different growing

This is an open access journal, and articles are distributed under the terms of the Attribution 4.0 International (CC BY 4.0) License. This license lets others distribute, remix, tweak, and build upon your work, even commercially, as long as they credit the author for the original creation. You must give appropriate credit, provide a link to the license, and indicate if changes were made. 
abiotic conditions such as varied altitudes, rainfall patterns and soil types that are associated with those growing locations [7]. The extracts of the leaves of the A. greatheadii, like those of other aloes, are reported to possess antioxidant properties [8]. However, there is no information on whether the variation in geographical locations has effect on the phytochemical contents and antioxidant capacity of the leaves of the plant species. The current study was aimed at the determination of the phytochemical contents and antioxidant capacity of the leaves of Aloe greatheadii collected from four provinces in South Africa, with the intention to establish whether variation in growing locations has effect on the phytochemical content and antioxidant capacity of the plant species.

\section{EXPERIMENTAL}

The leaves of Aloe greatheadii were collected from four different provinces (Limpopo, Gauteng, Mpumalanga and North West) using convenient sampling method. The Limpopo sample was collected at Polokwane along the Dendron road (altitude: $1329 \mathrm{~m}$ above sea level), Gauteng one was collected at Ga-Rankuwa (altitude: $1246 \mathrm{~m}$ above sea level), Mpumalanga one was collected at Siyabuswa (altitude: $1020 \mathrm{~m}$ above sea level) and the one from North West was collected at Brits (altitude: $1083 \mathrm{~m}$ above sea level).

The leaves from different locations were washed with distilled $\mathrm{H}_{2} \mathrm{O}$, chopped into smaller pieces and dried at room temperature. The dried plant samples were then ground into powder and stored in the dark using tightly closed containers until extraction.

Extraction: $5 \mathrm{~g}$ of the ground plant material from each province was poured was extracted in a serial sequential procedure with $50 \mathrm{~mL}$ of hexane, dichloromethane, acetone and methanol solvents using cold maceration extraction method. The extracts were then filtered into pre-weighed beakers, allowed to dry under a stream of air at room temperature and stored in the dark until further analysis.

\section{Phytochemical contents}

Total phenolic content: Total phenolic content was determined using the Folin-Ciocalteu assay as described by Tambe and Bhambar [9]. Standard solutions of gallic acid (20, 40, $60,80,100 \mu \mathrm{g} / \mathrm{mL}$ ) were prepared. About $1 \mathrm{~mL}$ of each of the gallic acid soloution was added to $9 \mathrm{~mL}$ of distilled water in a $25 \mathrm{~mL}$ volumetric flask. Then $1 \mathrm{~mL}$ of Folin-Coicalteu phenol reagent was added to the solution with shaking. After $5 \mathrm{~min}$, $10 \mathrm{~mL}$ of $7 \%$ sodium carbonate solution was added to the mixture. The solution in the flask was then incubated for 90 min at room temperature and the absorbance was recorded at $550 \mathrm{~nm}$. Solutions of leaf extracts of A. greatheadii were analyzed in the same manner described for standard solutions. Total phenol content of the extracts was expressed as gallic acid equivalence (GAE)/g dry weight of plant material.

Total tannin content: Total tannins content was determined using the Folin-Coicalteu assay as described by Tambe and Bambhar [9]. A standard curve was drawn with gallic acid standard solutions $(20,40,60,80,100 \mu \mathrm{g} / \mathrm{mL})$. About $0.5 \mathrm{~mL}$ of each of the gallic acid concentrations were added to a $50 \mathrm{~mL}$ volumetric flask containing $37.5 \mathrm{~mL}$ of distilled water. Then
$2.5 \mathrm{~mL}$ of Folin-Coicalteu phenol reagent and $1 \mathrm{~mL}$ of $35 \%$ $\mathrm{Na}_{2} \mathrm{CO}_{3}$ solution were added. The mixture was shaken and kept at room temperature for $30 \mathrm{~min}$. Absorbance was measured against the blank at $725 \mathrm{~nm}$. The leaf extracts of $A$. greatheadii were analyzed in the same manner described for standard solutions. Total tannin content in plant extracts was expressed as GAE/g dry weight of plant material.

Total flavonoid content: Total flavonoid content was measure by the aluminium chloride colorimetric assay as described by Tambe and Bhambar [9]. Standard solutions of quercetin $(20,40,60,80$ and $100 \mu \mathrm{g} / \mathrm{mL})$ were prepared from which about $1 \mathrm{~mL}$ was mixed with $4 \mathrm{~mL}$ of distilled water in a $10 \mathrm{~mL}$ volumetric flask. The mixture was then treated with about $0.30 \mathrm{~mL}$ of $5 \%$ sodium nitrate and $0.3 \mathrm{~mL}$ of $10 \%$ aluminium chloride was added was added after 5 min. After 5 min of incubation at room temperature, $2 \mathrm{~mL}$ of $1 \mathrm{M}$ sodium hydroxide was added and the mixture further diluted with 10 $\mathrm{mL}$ with distilled water. Absorbance was then read at $510 \mathrm{~nm}$. The leaf extracts of A. greatheadii were analyzed in the same manner described for standard solutions. Total flavonoid content in plant extracts was expressed as quercetin equivalence $(\mathrm{QE}) / \mathrm{g}$ dry weight.

Total saponin content: Estimation of total saponins content was determined by the method described by Makkar et al. [10], based on vanillin-sulphuric acid colorimetric reaction with some modifications. About $50 \mu \mathrm{L}$ of plant extract was added with $250 \mu \mathrm{L}$ of distilled water. To this solution, about $250 \mu \mathrm{L}$ of vanillin reagent ( $800 \mathrm{mg}$ of vanillin in $10 \mathrm{~mL}$ of $99.5 \%$ ethanol) was added. Then $2.5 \mathrm{~mL}$ of $72 \%$ sulphuric acid was added and it was mixed well. This solution was kept in a water bath at $60{ }^{\circ} \mathrm{C}$ for $10 \mathrm{~min}$. After $10 \mathrm{~min}$, it was cooled in ice cold water and the absorbance was read at $544 \mathrm{~nm}$. Total saponin content in plant extracts was expressed as diosgenin equivalents (DE)/g dry weight extract derived from the standard curve of standard solutions of diosgenin treated similarly to the plant extracts.

Total phytochemical content: The average values obtained for amounts of individual phytochemical groups (i.e., total phenolic, total tannin, total flavonoid and total saponin contents) for each sample from different locations were summed up to arrive at what was referred to as total phytochemical content. The location of the sample that the total phytochemical content was recorded at highest amounts was noted.

\section{Antioxidant activity strength}

DPPH assay: The free radical scavenging activity of the roots and leaves extract of the medicinal plant were compared to activity of a standard, vitamin C, as described by Abdille et al. [11], with slight modification. Serial dilutions (0-250 $\mu \mathrm{g} / \mathrm{mL}$ ) of the extract were prepared in $100 \mu \mathrm{L}$ using distilled water. Similar concentrations and volume of ascorbic acid were used as positive control. Then, $100 \mu \mathrm{L} 0.1 \mathrm{Mm}$ methanol solution of DPPH was added into the extracts solution and allowed to stand at room temperature for $30 \mathrm{~min}$. The changes in absorbance of the samples were measured at $550 \mathrm{~nm}$ using Multiskan Ascent plate reader (Thermo Labsystems, USA). The percentage inhibition of the extracts was calculated as follows:

$$
\text { DPPH inhibition }(\%)=\frac{\mathrm{A}_{\text {control }}-\mathrm{A}_{\text {extract }}}{\mathrm{A}_{\text {control }}} \times 100
$$




\begin{tabular}{|c|c|c|c|c|c|c|c|c|}
\hline \multirow{3}{*}{ Extracts } & \multicolumn{7}{|c|}{$\begin{array}{c}\text { TABLE-1 } \\
\text { TOTAL PHENOLIC, TANNIN, FLAVONOID AND SAPONIN CONTENTS OF THE } \\
\text { EXTRACTS OF A. greatheadii LEAVES FROM FOUR SOUTH AFRICAN PROVINCES }\end{array}$} & \multirow[b]{2}{*}{$\begin{array}{l}\text { North West } \\
\text { province }\end{array}$} \\
\hline & $\begin{array}{l}\text { Limpopo } \\
\text { province }\end{array}$ & $\begin{array}{l}\text { Gauteng } \\
\text { province }\end{array}$ & $\begin{array}{l}\text { Mpumalanga } \\
\text { province }\end{array}$ & $\begin{array}{l}\text { North West } \\
\text { province }\end{array}$ & $\begin{array}{l}\text { Limpopo } \\
\text { province }\end{array}$ & $\begin{array}{l}\text { Gauteng } \\
\text { province }\end{array}$ & $\begin{array}{l}\text { Mpumalanga } \\
\text { province }\end{array}$ & \\
\hline & \multicolumn{4}{|c|}{ Total phenolic content (mg GAE/g extract dry weight) } & \multicolumn{4}{|c|}{ Total tannins content (mg/GAE/g dry weight) } \\
\hline Hexane & 1.91 & 0.86 & 1.39 & ND & 0.068 & ND & ND & 0.153 \\
\hline DCM & 2.14 & 1.48 & 3.85 & 2.12 & 0.089 & ND & 0.368 & 0.239 \\
\hline Acetone & 3.27 & 2.20 & 3.93 & 1.95 & 0.261 & 0.026 & 0.410 & ND \\
\hline Methanol & 1.65 & 2.82 & 1.61 & 1.65 & 0.389 & 0.346 & ND & 0.111 \\
\hline \multirow[t]{2}{*}{ Average } & 2.24 & 1.84 & $2.63 *$ & 1.43 & $0.202 *$ & 0.093 & 0.195 & 0.126 \\
\hline & \multicolumn{4}{|c|}{ Total flavonoids content (mg/GAE/g extract dry weight) } & \multicolumn{4}{|c|}{ Total saponins content (mg/GAE/g extract dry weight) } \\
\hline Hexane & 2.47 & 2.97 & 2.04 & 1.35 & 0.275 & 0.315 & 0.279 & 0.269 \\
\hline DCM & 2.01 & 1.06 & 1.92 & 1.49 & 0.324 & 0.527 & 0.415 & 0.239 \\
\hline Acetone & 2.78 & 0.61 & 0.82 & 0.686 & 0.405 & 0.223 & 0.276 & 0.177 \\
\hline Methanol & 3.57 & 0.73 & 1.32 & 1.23 & 0.271 & 0.238 & 0.204 & 0.146 \\
\hline Average & $2.71 *$ & 1.34 & 1.52 & 1.19 & 0.319 & $0.326^{*}$ & 0.294 & 0.208 \\
\hline
\end{tabular}

Values calculated using the average absorbance of triplicates; *recorded highest amount amongst samples; ND: not determined.

The antioxidant activity strength of the methanol extracts of the leaves of A. greatheadii collected from four South African provinces was determined through the effective concentration that gave $50 \%$ DPPH inhibition that was extrapolated from the plot of the \% DPPH inhibition vs. extract concentration. The lowest or lower value was regarded as demonstration of highest or higher antioxidant activity strength.

\section{RESULTS AND DISCUSSION}

The extracts of the leaves of A. greatheadii from four South African provinces were subjected to quantitative phytochemical analysis for the determination of total phenolic contents, total tannin contents, total flavonoid contents and total saponins contents. The results of the phytochemical quantities determined within extracts of samples from different locations are shown in Table-1. On average, the high amount of total phenolics was recorded with Mpumalanga province sample; high amounts of tannins and flavonoids were recorded with the Limpopo province sample and the high amount of saponins was recorded with the Gauteng province sample. The results of the calculated total phytochemical content of samples are shown in Table-2. The highest total phytochemical content was recorded with the Limpopo province sample $(5.47 \mathrm{mg} / \mathrm{g}$ dry weight), followed by the Mpumalanga province sample $(4.64 \mathrm{mg} / \mathrm{g}$ dry weight) and the Gauteng province sample (3.59 $\mathrm{mg} / \mathrm{g}$ dry weight), with the North West province sample (2.95 $\mathrm{mg} / \mathrm{g}$ dry weight) recording the lowest total quantitative phytochemical composition.

\section{TABLE-2}

TOTAL PHYTOCHEMICAL CONTENT OF THE LEAVES OF A. greatheadii FROM FOUR SOUTH AFRICAN PROVINCES

\begin{tabular}{lcccc}
\hline & \multicolumn{4}{c}{ Phytochemical contents (mg/g dry weight) } \\
\cline { 2 - 5 } Phytochemical & $\begin{array}{c}\text { Limpopo } \\
\text { province }\end{array}$ & $\begin{array}{c}\text { Gauteng } \\
\text { province }\end{array}$ & $\begin{array}{c}\text { Mpumalanga } \\
\text { province }\end{array}$ & $\begin{array}{c}\text { North- } \\
\text { West } \\
\text { province }\end{array}$ \\
\hline Total phenolics & 2.24 & 1.84 & 2.63 & 1.43 \\
Total tannins & 0.202 & 0.093 & 0.195 & 0.126 \\
Total flavonoids & 2.71 & 1.34 & 1.52 & 1.19 \\
Total saponins & 0.319 & 0.326 & 0.294 & 0.208 \\
Total & $5.47^{*}$ & 3.59 & 4.64 & 2.95 \\
\hline
\end{tabular}

*Recorded highest amount amongst samples
The evaluation of antioxidant activity of the methanol extracts of the plant samples was done based on DPPH inhibition (Fig. 1). The methanol extract of the samples from all four provinces showed free radical scavenging properties against DPPH in a dose-dependent manner. The antioxidant activity strength was evaluated through the determination of $\mathrm{EC}_{50}$ of the samples extracts from the \% DPPH inhibition versus concentration plot and the $\mathrm{EC}_{50}$ values extrapolated from the antioxidant activity figure are shown in Table-3. The samples from the Limpopo and Mpumalanga provinces recorded the lowest $\mathrm{EC}_{50} \mathrm{~S}$ of 0.42 and $0.43 \mathrm{mg} / \mathrm{mL}$, respectively that were not different from each other. The Gauteng and North-West provinces samples recorded $\mathrm{EC}_{50}$ values of 0.62 and $0.82 \mathrm{mg} /$ $\mathrm{mL}$, respectively.

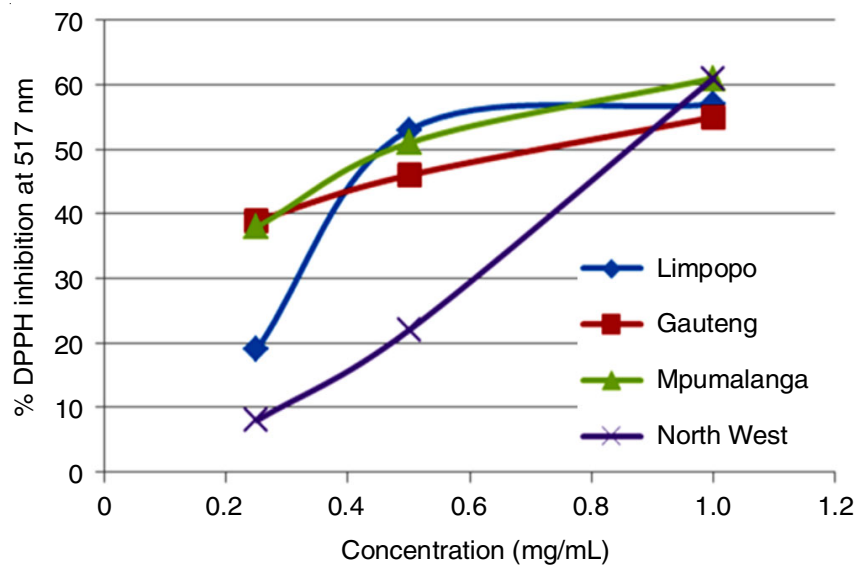

Fig. 1. \% DPPH inhibition of the methanol extracts of leaves of A. greatheadii collected from four South African provinces

TABLE-3

EC $_{50}$ VALUES OF THE METHANOL EXTRACTS OF THE LEAVES OF $A$. greatheadii FROM FOUR SOUTH AFRICAN PROVINCES AGAINST DPPH FREE RADICAL

\begin{tabular}{cc}
\hline Province & $\mathrm{EC}_{50}(\mathrm{mg} / \mathrm{mL})$ \\
\hline Limpopo & $0.42^{\mathrm{a}}$ \\
Gauteng & $0.62^{\mathrm{b}}$ \\
Mpumalanga & $0.43^{\mathrm{a}}$ \\
North West & $0.82^{\mathrm{c}}$ \\
\hline
\end{tabular}

${ }^{a, b, c}$ Values with different letters are significantly different at $\mathrm{p}<0.05$; values with similar letters are not significantly different at $p<0.05$ 
Quantitative phytochemical analysis is of significant importance in the study of medicinal plants since their biological activities have been shown to be dose-dependent in most cases $[12,13]$. In this study, quantitative phytochemical analysis was intended to determine the geographical location that, amongst other locations where samples were collected, affords high accumulation or amounts of tested phytochemicals. Determination of the amounts of phytochemicals within plant extracts entails spectrophotometric measurements of the colour intensity of the formed product upon reaction of the components of the extracts with a specific substrate [14]. Following spectrophotometric measurements, the amounts of phytochemicals are determined from the standard curves as equivalence of the concentration of standard compounds for a specific phytochemical group upon their reaction with a similar substrate under the same reaction conditions [9]. As such, total phenolic and tannin contents were expressed as gallic acid equivalence (GAE), total flavonoids were expressed as quercetin equivalence (QE) and total saponins were expressed as diosgenin equivalence (DE).

On average, the results showed the highest amounts of total phenolic content to be recorded with the Mpumalanga province sample; the highest amounts of tannins and flavonoids were recorded with the Limpopo province sample and the highest amounts of saponins to be recorded with the Gauteng province sample. The North-West province sample recorded none of the phytochemicals in highest amounts. In previous studies, higher altitudes were also linked with higher phytochemical amounts in medicinal plants [15-17]. However, in this study the different phytochemicals were recorded in higher amounts in samples from various locations. Since the different locations under study are of different altitudes, phytochemical group specificity upon influence of varied altitudes is therefore suggested. The suggested specificity in phytochemical groups accumulation specificity at different altitudes demonstrated through the results of the current study is in agreement with the results of a study by Nchabeleng et al. [18], where total polyphenols were found in wild bush tea samples growing at high altitudes whereas the accumulation of tannins was high at low altitudes in wild bush tea.

Confronted by similar observations of phytochemical specificity upon influence by varied geographical locations on the leaves of Senna italica, Gololo et al. [19] presented the comparative quantitative phytochemical analysis in the form of a concept referred to as the total phytochemical content that is achieved through the summation of the recorded individual phytochemical amounts. The results showed a high total phytochemical content to be recorded with the Limpopo province sample, followed by the Mpumalanga province sample and in turn followed by the Gauteng province sample, with the North-West province sample recording a low total phytochemical content. The sampling location at the Limpopo province area is of higher altitude compared to those of other sampling areas. Therefore, the results in terms of the total phytochemical content suggest that the phytochemical content was high at the location with a higher altitude. Therefore it appears that variation in geographical location have effect on the phytochemical content of the leaves of $A$. greatheaddi.
Most plants reported to possess some antioxidant properties to exhibit many other biological activities such as antidiabetic, anticancerous, antiatherosclerosis and antimicrobial activities [20]. For the current study, antioxidant capacity was evaluated using only the methanol extracts since previous studies has shown that methanol affords extraction of most antioxidant compounds from medicinal plants parts than other solvents $[21,22]$. The antioxidant capacity was determined using the effective concentration that gave $50 \%$ inhibition $\left(\mathrm{EC}_{50}\right)$ against DPPH free radical, with the lower values indicating higher antioxidant strength or capacity. The results of the current study showed some variation in the antioxidant capacity of the methanol extracts of the leaf samples of A. greatheadii from the different locations. The results further indicated higher antioxidant activity in the methanol extracts of leaf samples from Limpopo and Mpumalanga provinces as signified by lower $\mathrm{EC}_{50}$ values of 0.42 and 0.43 $\mathrm{mg} / \mathrm{mL}$, respectively, compared to relatively higher $\mathrm{EC}_{50}$ values for samples from the Gauteng and North-West provinces. Interestingly, the Limpopo province sample recorded the highest total phytochemical content as well as the highest antioxidant capacity; whereas the North West province sample recorded the lowest total phytochemical content and the lower antioxidant capacity. The results therefore suggest a positive relationship in the total phytochemical content and the antioxidant capacity of the leaves of A. greatheadii. This deduced observation is in agreement with the findings of the study by Aburigal et al. [23] where variation in the antioxidant capacity of Ocimum basilium collected from different regions and a positive relationship in the antioxidant capacity and total phenolic content were reported.

\section{Conclusion}

The leaf samples of A. greatheadii from four South African provinces showed some variation in the phytochemical contents and antioxidant capacity. The Limpopo province sample with the highest altitude, appeared to be providing suitable conditions for high accumulation of phytochemicals and higher antioxidant capacity. Therefore, the study demonstrated that variation in geographical locations has effect on the phytochemical contents and antioxidant capacity of the leaves of $A$. greatheadii.

\section{ACKNOWLEDGEMENTS}

The authors would like to acknowledge the Department of Biochemistry at Sefako Makgatho Health Sciences University for the facilities used to do the study and Dr. Bronwyn Egan, Department of Botany (University of Limpopo) for the taxonomic authentication of the plant species. The study was financially supported through the DHET Research Development Grant (RDG: GOLOLO) funding.

\section{CONFLICT OF INTEREST}

The authors declare that there is no conflict of interests regarding the publication of this article. 


\section{REFERENCES}

1. V.C. Graça, I.C.F.R. Ferreira and P.F. Santos, Ind. Crops Prod., 87, 363 (2016); https://doi.org/10.1016/j.indcrop.2016.04.058.

2. A.C. Figueiredo, J.G. Barroso, L.G. Pedro and J.J.C. Scheffer, Flav. Fragr. J., 23, 213 (2008); https://doi.org/10.1002/ffj.1875.

3. M.C. Inácio, T.A. Paz, B.W. Bertoni and A.M.S. Pereira, Acta Sci. Agron., 38, 467 (2016); https://doi.org/10.4025/actasciagron.v38i4.30567.

4. M.S. Hossain, A.N.M. Mamun-Or-Rashid, N.M. Towfique and M.K. Sen, J. Intercult. Ethnopharmacol., 2, 113 (2013); https://doi.org/10.5455/jice.20130612035300.

5. D.T. Loots, F.H. van der Westhuizen and L. Botes, J. Agric. Food Chem., 55, 6891 (2007); https://doi.org/10.1021/jf071110t.

6. B. Van Wyk and G. Smith, Guide to the Aloes of South Africa, Briza Publications: Pretoria, pp. 1-376 (1996).

7. W. Liu, J. Liu, D. Yin and X. Zhao, PLoS One, 10, e0122981 (2015); https://doi.org/10.1371/journal.pone.0122981.

8. L. Botes, F. Van der Westhuizen and D. Loots, Molecules, 13, 2169 (2008); https://doi.org/10.3390/molecules13092169.;

9. V.D. Tambe and R. Bhambar, Res. Rev. J. Pharmacog. Phytochem., 2, 41 (2014).

10. H.P.S. Makkar, M. Blummel, K. Borowy and K. Becker, J. Agric. Food Sci., 61, 161 (1993); https://doi.org/10.1002/jsfa.2740610205.

11. M. Abdille, R.P. Singh, G.K. Jayaprakasha and B.S. Jena, J. Food Chem., 90, 891 (2005); https://doi.org/10.1016/j.foodchem.2004.09.002.

12. J.-S. Shin, S.-W. Hong, J.-G. Lee, Y.-M. Lee, D.-W. Kim, J.-E. Kim, D.-J. Jung, S.-K. An, N.-J. Hong, D. Kim, D.-H. Jin and S.-Y. Lee, Int. J. Mol. Med., 27, 401 (2011); https://doi.org/10.3892/ijmm.2011.599.
13. F. Shafiee, E. Khoshvishkaie, A. Davoodi, A. Dashti Kalantar, H. Bakhshi Jouybari and R. Ataee, Medicines, 5, 1 (2018); https://doi.org/10.3390/medicines5010001.

14. H.C. Maduka, A.A. Maduka, C.U. Agouru, B.K. Myke-Mbata, J.O. Ikwue, A.N. Okpogba, C.E. Ugwu, C.C. Dike, P.N. Ogueche, D.O. Ochalefu, N. Ofaryana, J. Yakubu and E. Shatar, J. Adv. Med. Pharm. Sci., 15(2), 1 (2017); https://doi.org/10.9734/JAMPS/2017/30052.

15. M. Ganzera, M. Guggenberger, H. Stuppner and C. Zidorn, Planta Med., 74, 453 (2008); https://doi.org/10.1055/s-2008-1034326.

16. T.I. Borokini and A.E. Ayodele, Int. J. Modern Bot., 2, 97 (2012).

17. C.S. Ubani, O.A. Oje, F.N.P. Ihekogwo, E.A. Eze and C.L. Okofor, Global Adv. Res. J. Microbiol., 1, 120 (2012)

18. L. Nchabeleng, F.N. Mudau and I.K. Mariga, J. Med. Plants Res., 6, 1662 (2012); https://doi.org/10.5897/JMPR11.1453.

19. S.S. Gololo, N.S. Mapfumari and M.A. Mogale, Int. J. Pharm. Pharm. Sci., 10, 67 (2018); https://doi.org/10.22159/ijpps.2018v10i2.22950.

20. A.A. Shad, S. Ahmad, R. Ullah, N.M. AbdEl-Salam, H. Fouad, N.U. Rehman, H. Hussain and W. Saeed, Sci. World J., 2014, 1 (2014); https://doi.org/10.1155/2014/857363.

21. M. Kotze, J.N. Eloff and P.J. Houghton, S. Afr. J. Bot., 68, 62 (2002); https://doi.org/10.1016/S0254-6299(15)30442-7.

22. P. Masoko and J.N. Eloff, Afr. J. Tradit. Complement. Altern. Med., 4, 231 (2007).

23. Y.A.A. Aburigal, M.E.S. Mirghani, E.Y. Elmogtaba, A.A.M. Sirible, N.B. Hamza and I.H. Hussein, Int. Food Res. J., 24, S378 (2017). 